\title{
PROBLEMATIC ASPECTS OF THE INTERPRETER'S PARTICIPATION IN CRIMINAL PROCEEDINGS
}

\author{
Iuliia Nozdracheva \\ Teacher, RUDN University, Law Institute Foreign Languages Department, \\ RUSSIAN FEDERATION, \\ ylkaxd66@yandex.ru
}

\begin{abstract}
This article is devoted to the key problems which interpreters face when they participate in criminal proceedings. The paper also accumulates the opinion of legal experts on the topic under study. Respective problematic aspects have been identified by Russian and foreign researchers and practitioners who deal with the issue in practice, in criminal settings, and in the training fields, as well.

The article deals with organizational and procedural issues related to an interpreter's participation in criminal proceedings, interpreter's competence identification, possible unforeseeable errors which may arise in the course of interpreting.

The methodology combined theoretical and empirical studies, aggregated data from academic findings, analysis of some cases, information based on the activities of institutions which operate as linguistic and judicial expertise units, data received from specialists engaged in education policy. The paper also used the background provisions of the Code of Criminal Procedure of the Russian Federation which relate to the translator and interpreter's status.
\end{abstract}

The paper consistently explores the components of interpreter's competence that are mandatory for his/her efficient work in court within the broader context of the overall interpreter's work within the criminal settings. Interpreters' extralinguistic capacities and personal features are also subject to the investigation. Further the interpreter's impartiality, rights with regard to the participation in the proceedings draws the audience attention, as well. Some other extralinguistic points are in the focus of consideration, as well.

The findings have made it possible to identify some challenging points that refer procedural, recruiting, and qualification issues with regard to the interpreter's engagement in the criminal proceedings in Russia.

Keywords: Interpreting, criminal settings, interpreter's rights and obligations, and competences. Abstract text must be in one column and Arial font, 10 point, normal, justified alignment with single-spaced interline spacing.

\section{INTRODUCTION}

The long-standing practice of multilingual communication confirms that the translation and interpreting activities play a crucial role major societal contexts and settings (Atabekova, 2020)

Academia has paid consistent attention to the issues and challenges that emerge in the course of interpreter's engagement in the criminal proceedings.

Scholars explore the topic within the various domains including interpreter's training and legal grounds, consider the point within the issues of justice provision (Atabekova, 2016; Biel, 2011; Elias-Bursać, Askew, 2018; Lee, 2017), and ICT use to enhance the quality of service provision (Atabekova, 2018; Orozco Jutorán, 2018; Quattrocolo, 2020).

In Russia a number of offences are committed by people who do not have knowledge of the Russian language and this fact has reaffirmed the topicality of this article. Consequently, a frequent use of interpreter 
service is urgently needed especially during interrogations and trials. Meanwhile, legislation regulating interpreting activities contains a number of gaps.

Investigators and judges still face the problem of organization of a court session where interpreter service is necessary, they hardly know where to obtain proper interpreter service and how to pay for interpreters' work. In practice advocates may challenge an interpreter on the pretext of the absence of a diploma degree which on the statutory level can prove their competence or they challenge an interpreter due to the fact that skills and quality of service provision do not correspond to the needs and formats of the court session.

The research goal is to explore mistakes and consider recommendation aimed at facilitating the workload of law-enforcement bodies.

The methodology integrated desk and field research, and aggregated data from academic findings, analysis of some cases, information based on the activities of organization which operate as linguistic and judicial expertise units, data received from specialists engaged in education policy.

All the text must be in one column and Arial font, 10 point, normal, justified alignment, including figures and tables, with single-spaced interline spacing.

\section{RESULTS AND DISCUSSION}

Due to the acceleration of some current globalization processes Russia is intensively implementing intercultural interaction with other countries in different sectors such as manufacturing, trade, construction, external policy and development of economic ties and others and these aforementioned facts can identify the topicality of this article, inter alia, the burst of emigration to Russia, thereby may have a negative impact on law and order inside the territory of the Russian Federation, because there is a record of cases initiated which involves the participation of foreign citizens of neighboring countries who play different roles: as criminals, victims, witnesses, suspects, defendants and etc. All these circumstances set a breeding ground for getting an access to duly provided interpreting services which can be considered as a key to qualitative and successful investigation.

To recruit the right person for interpreting provision is challenging. First, there is a necessity to hire an interpreter of the appropriate language it is quite difficult sometimes within the same city; second, it is urgently required to ascertain whether he or she is competent enough to provide these interpreting services since the obtaining degree in interpreting or translation frequently does not imply language proficiency and enhanced knowledge of professional legal terminology.

Third, adjustment to interaction with an interpreter may also be potentially at fault, adapting to a personality, with whom you are about to interact on all procedural stages, is essential. All factors must be taken into consideration. Highly important of them for cooperation are the following: personal qualities, experience, intelligence, moral principles, impartiality, the knowledge of code of ethics, responsibility for reliability and accuracy of provided data, psychological stability. Next, we will study in detail what organizational and procedural difficulties may occur if an interpreter is highly required to participate in criminal proceedings.

Challenges which arise in the course of criminal proceedings attract many researchers, there is more work to be done and these issues described in the works of scientists analyzed in this article are concretized below.

- The language for filing and conducting proceeding. It presupposes the right to use the native language in criminal proceeding regardless of what language is officially recognized. The right to access a free of charge interpreting service provision. Free of charge means it is financed from public purse. This right is a constitutional one.

The legal status of an interpreter or a translator. Contentious issues and problematic aspects regarding the legal status of an interpreter are being examined and some ways to tackle the problems have been proposed.

- Specific knowledge in criminal proceedings. These works emphasize the importance of the participation of a competent person having enhanced expertise knowledge in criminal proceedings to provide assistance in the warning, detection, prevention, prediction of offences; problems which may occur in the course of criminal proceedings in case of absence of expertise knowledge are listed.

- Features of investigation of criminal cases with the participation of an interpreter - these authors describe related problems, tactics and applied methods used while investigation in criminal proceedings with the participation of an interpreter;

- Participation of the interpreter at various stages of criminal proceedings - these works involve the description of the peculiarities of the interpreter's participation during the various stages of criminal 
proceedings. Possible constraints and ways to resolve them are also identified within the framework of the research conducted by them.

The above-mentioned problems regarding interpreter's participation in criminal proceedings are of a theoretical nature. There is a need for further discussing issues which can be faced by interpreters in practice.

Among other issues we consider it possible to mention the following.

The organizational and procedural issues connected with a participation of an interpreter in criminal proceedings should deserve a particular attention.

The above refers to the question on how to find the right candidature for interpreting services provision/ Currently, an expert body has not been established in Russia that could provide translators of the necessary languages for participation in criminal proceedings, and therefore, it is worth denoting that the process of identifying qualified translators may take longer than expected and different ways and means are being used for conducting such a search:

- Through close acquaintanceship

- Via the Internet

- By means of putting in a request with translation agencies or bureaus (they do not function in every city), etc.

The situation is getting complicated in the case of hiring a specialist who speaks a rare language, such as Chinese, Persian, sign language, etc.: in this case, it is possible to search for an interpreter in other cities or countries. In our opinion, the establishment of a special expert translation body with a branch in each region of Russia would help to solve this problem.

Furthermore, an interpreter may reject the proposal to be involved in criminal proceeding due to several reasons and some of them are listed below:

Frequently, interpreters are engaged in many areas and are employed simultaneously in different agencies. Hence, the second reason is employer's reluctance to allow an interpreter work in the other workplace.

Also, interpreters can be unable to take their duties for fear of being attacked and psychologically intruded by the parties in criminal proceedings. In addition to this, interpreters are not ready to be engaged to participate in criminal proceedings because they can be put pressure on by the parties of the proceeding through threats or force to take sides and to provide false interpreting deliberately. Poor wages, inappropriate location and stressful working conditions are also can be considered as the underlying factors that may trigger unwillingness to take part in process.

The solution to this problem can be an official invitation to appear in court session by issuing a summons against an interpreter. However, such a measure has not expressly been stipulated in the Code of Criminal Procedure of the Russian Federation. Thus, this problem remains relevant at present.

Recusal or self-disqualification is controversial in criminal court proceeding. Many scientists suppose that Code of Criminal Procedure of the Russian Federation does not stipulate an interpreter's right to refuse from participation in criminal proceeding without having special skills and knowledge in interpreting sphere or for other reasons, so this fact makes an interpreter vulnerable and infringe the rights of an interpreter.

Procedural incompetence of an interpreter should be also discussed: participants in criminal proceedings are obliged to adhere to a certain scenario set forth in a specific procedural action: an interpreter's knowledge of a foreign language does not guarantee understanding of the scenario of a specific procedural action and behavioral etiquette in the course of a trial, therefore, an interpreter shall beforehand examine the scope of his or her rights and obligations as a participant in criminal proceedings. Violations of the scenario of conducting a procedural action and distortion of its outcomes can be caused in a result of the following mistakes made by interpreters: excessive empathy is demonstrated on the part of an interpreter toward any of the participants in criminal proceedings (when an interpreter unconsciously or deliberately takes any of the sides during criminal proceedings).

Influence of an interpreter on any of the sides of the proceeding might be considered as incompetent behavior wherein any kind of actions including non-statutory advice, recommendations, estimations, comments, value judgements, inducements to action may undermine reputation and make interpreter's behavior unprofessional. Initiation of the course of criminal proceedings by an interpreter is also 
inappropriate (an interpreter independently asks questions, gives instructions to the participants of criminal proceedings, though it is not his or her scope of work, these actions must be undertaken by the authorized person; if these procedures had not been undertaken, an interpreter should have waited for this person responsible for such procedures. Disclosure of data obtained in the course of criminal proceedings by an interpreter is strictly prohibited.

The charges for services rendered by an interpreter in criminal proceedings is a sensitive issue: services provided by an interpreter in criminal proceedings, opposed to civil and administrative proceedings, are subject to payment (Decree of the Government of the Russian Federation dated 1 December 2012 No. 1240), and, at first glance, it seems that this issue does not provide difficulties, but in fact, we have to face a wide range of impediments:

Preparation of necessary documents for payment (service provision agreement, work completion statements, payment request for services provision) takes a lot of time. Law enforcement officers significantly delay execution of these documents, due to heavy workload, therefore, the actual payment for translation services may be withheld up to a year from the end of a specific procedural action. At the stage of preliminary investigation, the investigator issues a ruling to pay for interpreting services, the same actions are undertaken by the judge upon completing the court session, a great deal of time is needed to bring this ruling into action, to comply all formalities and get the payment procedures done. As for timing of interpreting, it is calculated according to records kept in interrogation, submission or any other protocols regarding conducting the concretized procedural actions, the waiting time of the initiation of this action (which may take more than 7 hours) and time interval between the initiation of one action and winding up the other one is not compensated. These above illustrated circumstances cause interpreters' discontent and unwillingness to act as an interpreter in court session.

Counting translated pages in case of written translation: 1,800 printed characters, including punctuation marks and spacebars, are considered to be one translation page. Common mistakes in counting translation pages are the following: a) ignoring spacebars; b) counting is often carried out according to the number of pages", not according to "characters" (depending on the font size - there may be from 1 to 5 or more translation pages on one actual page); c) counting characters of the translated text, instead of the original text (with hieroglyphic writing, the number of characters of the original text and the translation text may differ significantly). A separate difficulty is the counting of characters in the handwritten text, because it takes a huge amount of time.

So, the key organizational and procedural problems have been analyzed that may arise in the framework of the participation of an interpreter in criminal proceedings. Some further aspects of a bit different nature will be taken into account.

It is worth ascertaining an interpreter's competency and professionalism. Analyzing scientific studies on the topic of participation of an interpreter in criminal proceedings it can be concluded that many authors pay attention to the fact that currently the Russian legislation has not solved the problems which occur while choosing a candidature for accomplishing translators or interpreters' tasks, since the criminal procedure law does not define the concretized criteria for their competence, linguistic characteristics, level of appropriate education, which should be taken into consideration by authorized personnel responsible for conducting criminal proceedings when appointing an interpreter. Some authors propose to consider the competence of an interpreter in two ways: "as a capability of the individual and as a requirement established by law: in the first case, a person may have competence, regardless of whether he or she is involved in criminal proceedings or not. The second way is compliance with the legal requirements which presupposes knowledge and competence assessment by different means and methods established by the Criminal Procedural Code of the Russian Federation (Tarasenko, Shekhovtseva, 2018).

\section{CONCLUSION}

Taking into account the above-mentioned information, competency is understood as a set of characteristics and requirements set forward toward a candidate. This wide range of features include: possession of certificate which confirms knowledge of a foreign language (a diploma of higher education establishment recognized by the State) which will give an opportunity to act as an interpreter, so called cultural competence (knowledge about cultural peculiarities, traditions, customs of the target language), professional and ethical competence (outward appearance and dress code appropriate for the situation, adherence to code of ethics and manuals how to behave in a court session), possession of legal terminology, procedural competence; general knowledge of the legislation of the country of the language being translated or interpreted, etc. (Bondi, 2004). 
Thus, it is obvious that the participation of an interpreter itself intrudes standard operating procedure, because its participants, who do not speak a foreign language, depend on the interpreter; in addition, there are a number of factors which may undermine the quality of dispute resolution. Therefore, it is highly needed to establish a special expert body in order to optimize the process of criminal proceedings in the Russian Federation and these undertaken actions will facilitate the participation of interpreters.

As for competence of interpreters and translators it is not enough to have a certificate of higher education establishment which can prove the level of language competence. A particular advantage would be a second degree in law since an interpreter must understand what exactly the term means from legal perspective. So some extra knowledge connected with procedural rules, norms and judicial aspects are highly needed.

The following aspects have been touched upon: search for a candidate who speaks the required language or dialect; selection of an interpreter of the required gender; exclusion of the likelihood of procedural incompetence of a candidate; transportation of an interpreter to the place of a specific procedural action / or carrying out these actions on the territory of an expert translation body; timely payment for translation or interpreting services; formation of a database of incompetent translators, or translators who have violations when participating in criminal proceedings. Summing up, it is also worth singling out a number of criteria of a potential expert body which will be responsible for training and providing assistance through selection of qualified interpreters.

This independent body should have its own staff of certified translators and interpreters who will be able to operate in different languages that are in demand in judicial and investigative practice with the maximum choice among translators of the same languages; agree to bear financial and other responsibility for noncompliance with procedural norms (disclosure of the secrets within the framework of investigation, unfair and indecent behavior of translators or interpreters); have good business reputation and experience in working with judicial and law enforcement agencies.

\section{REFERENCE LIST}

Atabekova, A. (2016) Choosing Sources for Translation to Support Human Rights: Quality and Competence Issues. EDULEARN16 -Proceedings of 8th International Conference on Education and New Learning Technologies. IATED, Spain, 2972-2977.

Atabekova, A. (2018). ICT Tools for Interpreters: Is Academia ready for Industry Digital Development? 12th International Technology, Education and Development Conférence (INTED). Valencia, SPAIN, pp. 8708-8712

Atabekova, A. (2020). University Discourse to Foster Youth's Sustainability in Society amidst COVID19: International and Russian Features. Sustainability, 12, 7336.

Biel, Ł. (2011). Professional realism in the legal translation classroom: Translation competence and translator competence. Meta, 56(1), 162-178.

Bondi, M. (2004). If you think it sounds very complicated, you are correct": Awareness of cultural difference in specialized discourse. In C.N. Cadlin \& M. Gotti (Eds.), Intercultural aspects of specialized communication. 53-78. Bern: Peter Lang AG, European Academic Publishers.

Elias-Bursać, E., \& Askew, L. (2018). Translation and international justice (pp. 177-192). London: Routledge.

Lee, J. (2017). A case study of interpreter-mediated witness statement: police interpreting in South Korea. Police Practice and Research, 18(2), 194-205.

Orozco Jutorán, M. (2018). The TIPp project: developing technological resources based on the exploitation of oral corpora to improve court interpreting. InTRAlinea. Online Translation Journal, (20).

Quattrocolo, S. (2020). Artificial Intelligence, Computational Modelling and Criminal Proceedings: A Framework for a European Legal Discussion (Vol. 4). Springer Nature.

Shigurov, A. V., \& Lemaykina, Y. A. (2015). The Problem of Evaluating the Competence of the Translator in the Russian Criminal Trial. Economics \& Law, 50(4).

Tarasenko, V. V., Shekhovtseva, T. M. (2018). Some Problems of Participation of a Translator in the Criminal Proceedings of the Russian federation. In Experientia est optima magistra (pp. 271-273). 